\title{
P03-028 - Spectacular efficiency of isotretinoin in small doses in the sebopsoriasis treatment
}

\author{
M Mael-Ainin ${ }^{1 *}$, H Boudhir $^{1}$, A Saidi ${ }^{2}$, K Senouci $^{1},{ }^{3}$ Hassam ${ }^{1}$ \\ From 7th Congress of International Society of Systemic Auto-Inflammatory Diseases (ISSAID) \\ Lausanne, Switerland. 22-26 May 2013
}

\section{Introduction}

Sebopsoriasis is a chronic erythematous scaly dermatitis that is inconveniencing due to its showing character and the frequent inefficiency of the various treatments used. We report through this case the efficiency of low-dose isotretinoin in this particular form of psoriasis.

\section{Objectives}

To emphasize on isotretinoin low-dose efficiency in sebopsoriasis treatment.

\section{Methods}

Miss H.B, 30 years old, with a history of a psoriasis in the father. The patient was followed up for two years for a histologically confirmed sebopsoriasis. She received various therapies, initially put on moisturizers and Imidazoles but with no improvement, then on dermocorticoids and vitamin $\mathrm{D}$ derivatives. Treatment with UVB phototherapy could not be achieved, given the professional constraints of the patient. She was put on Methotrexate at $12.5 \mathrm{mg} /$ week dose for six months without improvement. Treatment based on $5 \mathrm{mg}$ Isotretinoin, three times per week, was recommended allowing the complete whitening of lesions two months after the start of treatment with the benefit of one year hindsight.

\section{Results}

The sebopsoriasis alters significantly the quality of life of patients. The treatment is mainly based on local treatments but those are often ineffective. Phototherapy or other systemic therapies are also used with varying results. These centro-facial effects during psoriasis respond well to small doses of isotretinoin at the rate of

'Dermatologie - Vénérologie, Centre Hospitalier Universitaire IBN Sina, Morocco

Full list of author information is available at the end of the article
$5 \mathrm{mg}$ three times per week or every day, which is well illustrated through this observation.

\section{Conclusion}

Our case shows a remarkable efficiency with a good tolerance of isotretinoin in sebopsoriasis treatment. This promising result should prompt us to use more this retinoid in the treatment of this particular form of psoriasis.

\section{Disclosure of interest}

None declared.

\section{Authors' details}

'Dermatologie - Vénérologie, Centre Hospitalier Universitaire IBN Sina, Morocco. ${ }^{2}$ Centre of Anatomic Pathology, United Nations, Rabat, Morocco.

Published: 8 November 2013

doi:10.1186/1546-0096-11-S1-A226

Cite this article as: Mael-Ainin et al:: P03-028 - Spectacular efficiency of isotretinoin in small doses in the sebopsoriasis treatment. Pediatric

Rheumatology 2013 11(Suppl 1):A226.

Submit your next manuscript to BioMed Central and take full advantage of:

- Convenient online submission

- Thorough peer review

- No space constraints or color figure charges

- Immediate publication on acceptance

- Inclusion in PubMed, CAS, Scopus and Google Scholar

- Research which is freely available for redistribution

\section{Biomed Central}

